\title{
EXPERIENCIAS PLURILINGÜES EN LA ENSEÑANZA DE LENGUAS EXTRANJERAS
}

Aicinburu, María Cecilia (ed.) (2017). Experiencias plurilingües en la enseñanza de lenguas extranjeras. Barcelona: Octaedro. ISBN: 978-84-9921-996-7, 138 páginas, 11,99€.

La obra colectiva Experiencias plurilingües en la enseñanza de lenguas extranjeras, publicada en la colección de Educación Superior de la editorial Octaedro bajo la dirección editorial de María Cecilia Ainciburu, supone una valiosa contribución para el plurilingüismo y la enseñanza/aprendizaje de lenguas extranjeras «en una realidad, europea e internacional, profundamente cambiada en los últimos años» (p.7), en la que tanto la lingüística aplicada como la didáctica de las lenguas extranjeras han tenido que aprender a adaptarse a nuevos escenarios educativos. La presente obra está especialmente dirigida a investigadores y profesores de lenguas extranjeras que han de responder a los nuevos retos de la Europa del siglo XXI. El libro es una obra colectiva de 138 páginas en la que participan trece investigadores con experiencias directas en la enseñanza de diferentes lenguas extranjeras (alemán, español, inglés, francés y portugués) en contextos plurilingües. Las distintas investigaciones presentadas en este volumen, articuladas en nueve capítulos, reflexionan sobre las características particulares de la adquisición y enseñanza de lenguas en situaciones multiculturales y plurilingües, además de presentar los principios teóricos más significativos dentro de este campo de la lingüística aplicada.

En el primer capítulo, con el título «La importancia de la notación en acero y hormigón pretensado ${ }^{1} »$, Eve Bauder señala la repercusión de la correcta comprensión de la notación dentro de la ingeniería mediante la indagación de su valor semántico y las implicaciones didácticas que esto conlleva dentro de la enseñanza y adquisición terminológica. Este trabajo supone una relevante aportación en un intento de «comprender los procesos de variación y normalización que están bajo la elección de un determinado término, un símbolo o de una cantidad en textos de ingeniería estructural» (p.9).

En el segundo capítulo, «La retórica intercultural, una nueva vuelta de tuerca a la retórica contrastiva y al análisis contrastivo de la expresión escrita», David Heredero

1 Artículo escrito en alemán con el título original «Die große Unbekannte: die Bedeutung der Notation in stahl und Spannbeton». 
presenta la evolución experimentada en los últimos cincuenta años por la retórica cultural, desde sus orígenes con la retórica contrastiva hasta la reconceptualización llevada a cabo por Connor (1996), quien acuñará el nuevo término y ampliará la disciplina con la integración de los «factores sociales, culturales, educativos y personales que participan durante la creación de un texto» (p. 27). Por lo que respecta a la situación de la retórica intercultural en el ámbito hispano, el autor describe las aportaciones realizadas hasta el momento, si bien señala que, aunque existen numerosos trabajos, es una disciplina que todavía dista mucho de alcanzar la ya asentada tradición anglosajona.

En el capítulo, «Antecedentes de la ansiedad comunicativa en estudiantes universitarios: percepción de la producción oral y actitudes hacia el español como lengua extranjera», Mercedes Rabadán Zurita y Alejandro Orgambídez Ramos determinan la importancia del papel de la autopercepción que de una lengua extranjera posee el aprendiente con respecto a su producción oral, y la repercusión que tiene sobre la ansiedad comunicativa. La investigación es llevada a cabo a través de un estudio empírico cuyos datos muestran que hay una correlación estadísticamente significativa entre los niveles de ansiedad y la autopercepción de la propia competencia por parte del aprendiente (a mejor autopercepción de la propia competencia, menor ansiedad). Dichos resultados revelan que «el nivel de conocimiento y el desarrollo de las competencias influyen en la participación del alumno determinando los niveles de ansiedad al realizar actividades comunicativas orales» (p.47).

Krastanka Bozhinova, en el capítulo titulado «Perfeccionamiento de la producción escrita en francés como L3 a través de herramientas digitales ${ }^{2} \gg$, se centra en la enseñanza/ aprendizaje del francés como lengua tercera dentro del ámbito académico en Bulgaria, cuyos estudiantes universitarios tienen como segunda lengua el inglés. Dicha investigación prioriza las necesidades de los aprendientes de nivel A1-B1 mediante el diseño de una propuesta que tenga en cuenta las dificultades de la producción escrita creativa y la comprensión lectora de las convenciones de intercambio en francés. La investigaciónacción llevada a cabo por la autora evidencia los efectos positivos del aprendizaje mixto o semipresencial (blended learning), que promueve el desarrollo y perfeccionamiento de la producción escrita de los sujetos de la investigación.

En el capítulo «Recursos de Internet para la enseñanza/aprendizaje del francés de los negocios ${ }^{3} »$, Thomas Lamouroux presenta una interesante selección de recursos de libre acceso en la red para la enseñanza/aprendizaje del francés de los negocios. Dichos recursos han sido clasificados teniendo en cuenta su valor didáctico (puesto que por un lado se trata de fuentes y documentos auténticos, y por el otro proporcionan una base de actualización inmediata de recursos). De igual modo, el autor realiza un sistematizado

2 Artículo escrito en francés con el título original «Améliorer la production écrite en français L3 à l'aide d'outils numériques».

3 Artículo escrito en francés con el título original «Ressources internet pour l'enseignement-apprentissage du français des affaires - français de l'entreprise». 
análisis de los recursos de internet en lo que se evalúan los aspectos positivos y negativos de cada uno de los recursos seleccionados.

Bajo el título «Liminalidad, hibridez y multiculturalismo en la literatura latinoamericana estadounidense ${ }^{4} \gg$, Luisa Sánchez Rivas y Marta Genís Pedra abordan el plurilingüismo y la multiculturalidad desde el concepto de la liminalidad, herramienta teórica que les sirve para entender el carácter híbrido de la cultura latina en Estados Unidos. Los autores exploran la liminalidad desde algunos trabajos de Ana Lydia Vega, Ernesto Quiñonez, Junot Díaz y Sandra Cisneros, representantes todos ellos de una literatura minoritaria e híbrida que plantea una nueva forma de expresión donde convive el español y el inglés. Este novedoso trabajo muestra cómo la liminalidad, en relación con la hibridación y el multiculturalismo, tiene una gran influencia en la construcción de la identidad en las culturas híbridas, y cómo esta condición puede ser potencialmente muy fértil en términos de producción artística y cultural. Estas características liminales les permiten «with a truly multicultural point of view to understand the world, crossing geographical, linguistic, narrative and ideological boundaries» (p. 81). Esta trabajo resulta, sin duda alguna, novedoso y actual para los estudiantes de ELE.

Beatriz López Medina y María Vaíllo Rodríguez ofrecen en el séptimo capítulo, «Bilingüismo y funciones ejecutivas: control de inhibición, atención y nivel de $\mathrm{L} 2^{5}$ », los resultados de su investigación cuyo objetivo ha sido la descripción de los factores que inciden en la interlengua de los estudiantes de lenguas extranjeras, esto es, encontrar las conexiones entre las dos funciones de la inteligencia ejecutiva (el control de la inhibición y la atención) en relación al nivel de la L2 por parte de estudiantes universitarios. Los resultados de la investigación empírica muestran la dificultad de mantener la atención en una tarea monótona cuando la competencia de la L2 es intermedia, por lo que las futuras intervenciones didácticas tendrían que incidir en el mantenimiento de la atención mediante tareas con mayor grado de repetitividad.

En el penúltimo capítulo, «Una nueva propuesta didáctica para la enseñanza-aprendizaje de las locuciones y los refranes en ELE», Clara Ureña Tormo nos ofrece, desde un enfoque comunicativo, una rigurosa propuesta didáctica para la enseñanza/adquisición de las unidades fraseológicas del español a través de la integración de las locuciones y refranes con el resto de los contenidos curriculares. Este novedoso tratamiento de dichas unidades lingüísticas permite, por un lado, distanciarte de la mayoría de los trabajos que hasta el momento lo han abordado de manera marginal, favoreciendo así sus «características formales, funcionales, semánticas y culturales» (p. 102), y por el otro, poner en relación las unidades fraseológicas de dos lenguas diferentes gracias a un análisis contrastivo.

4 Artículo escrito en inglés con el título original «Liminality, hybridity and multiculturalism in American Latino literature».

5 Artículo escrito en inglés con el título original «Bilingualism and executive functions: Inhibitory control, attention focus and second language level». 
El libro dedica el capítulo final «El sol está caliente, quiero una cerveza bien heladita: en busca de una sistematización de las inadecuaciones pragmáticas entre los hablantes brasileños de español como $\mathrm{L}^{6}{ }^{6} \gg$ al tema de las interferencias pragmáticas entre nativos y no nativos que va más allá de aquellas que regulan la adecuada formación de las estructuras gramaticales. El autor aborda dichas interferencias pragmáticas dentro de la interacción a través de un análisis contrastivo cuyos resultados dejan ver claramente que el origen de las transferencias negativas se debe ante todo al desconocimiento por parte del enunciador de la carga cultural o metafórica que estas poseen, hecho que tiene un efecto comunicativo de incomprensión en el interlocutor al no ser capaz de interpretarlas adecuadamente. Por lo tanto, el análisis de Martín Salcedo defiende una enseñanza de LE en la que se proporcionen «estratégias linguísticas básicas para compreensão e produção de sentidos, deve fomentar habilidades de cunho intercultural, principalmente no que se refere às questões pragmáticas» (p.116).

El presente volumen brinda al lector una serie de interesantes y novedosas aportaciones sobre el plurilingüismo desde muy diferentes perspectivas. La obra contrae uno de los grandes retos a los que la lingüística aplicada y la didáctica de las lenguas extranjeras ha tenido que asumir en el siglo XXI, «una situación en la que los viejos términos disciplinarios -bilingüismo, contrastividad, competencia cuasi nativa- quedan englobados y adquieren un significado que les distancia de la utopía y los acerca a una sustantividad que no tenían» (p.7).

6 Artículo escrito en portugués con el título original «El sol está caliente, quiero una cerveza bien heladita: em busca de uma sistematização das inadequações pragmáticas entre falantes brasileiros e espanhóis como L2». 